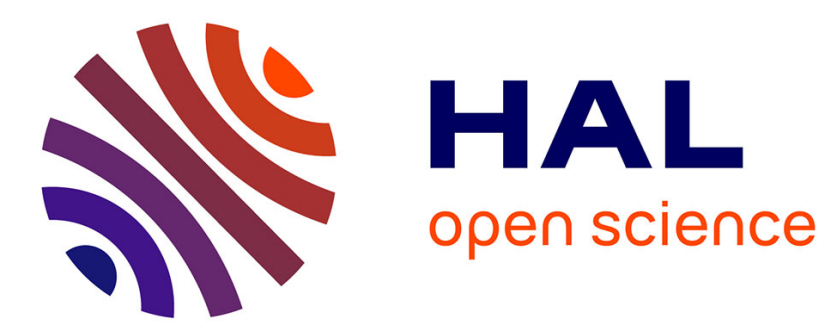

\title{
On the Mechanism of the Initial Permeability in MgMnZn-Ferrite
}

M. Kolenbrander, P. van Der Zaag

\section{To cite this version:}

M. Kolenbrander, P. van Der Zaag. On the Mechanism of the Initial Permeability in MgMnZn-Ferrite. Journal de Physique IV Proceedings, 1997, 07 (C1), pp.C1-195-C1-196. 10.1051/jp4:1997172 . jpa00255119

\section{HAL Id: jpa-00255119 https://hal.science/jpa-00255119}

Submitted on 1 Jan 1997

HAL is a multi-disciplinary open access archive for the deposit and dissemination of scientific research documents, whether they are published or not. The documents may come from teaching and research institutions in France or abroad, or from public or private research centers.
L'archive ouverte pluridisciplinaire HAL, est destinée au dépôt et à la diffusion de documents scientifiques de niveau recherche, publiés ou non, émanant des établissements d'enseignement et de recherche français ou étrangers, des laboratoires publics ou privés. 


\title{
On the Mechanism of the Initial Permeability in MgMnZn-Ferrite
}

\author{
M. Kolenbrander and P.J. van der Zaag* \\ Philips Components, Central Innovation Magnetic Products, BE-2, P.O. Box 218, 5600 Eindhoven, \\ The Netherlands \\ * Philips Research Laboratories, Prof. Holstlaan 4, 5656 Eindhoven, The Netherlands
}

\begin{abstract}
The magnetic permeability and the thickness of the so- called "non"- magnetic grain boundary were studied for a MgMnZn-ferrite with composition $\mathrm{Mg}_{0.8} \mathrm{Zn}_{0.2} \mathrm{Mn}_{0.1} \mathrm{Fe}_{1,85} \mathrm{O}_{3.925}$. For the mono-domain situation the grain size dependence of the effective initial permeability is well described by the nonmagnetic grain boundary model. A gradual increase of permeability with grain size around the transition from mono- to two-domain indicates that the permeability is predominantly rotational in origin. The intrinsic initial permeability and the "non"magnetic grain boundary width were obtained from a fit of permeability versus grain size at different temperatures. It is found that the grain boundary thickness decreases with temperature. This suggests that the grain boundary is hard magnetic rather than nonmagnetic.
\end{abstract}

\section{INTRODUCTION}

It is well known that the initial permeability of soft ferrites increases with grain size. Globus and co-workers [1] developed a model in which this grain size dependence is described by the bulging of intra-granular domain walls. More recently, a different model has been proposed [2,3]. In this nonmagnetic grain boundary (NMGB) model the initial permeability of polycrystalline ferrites is influenced by a "non"-magnetic grain boundary. In line with the idea, originally proposed by Snoek [4], it was suggested that the predominant mechanism for initial permeability is rotation of magnetisation.

In a recent neutron depolarisation experiment it was established that for a grain size $\mathrm{D}<3.8 \mu \mathrm{m}$ intra-granular domain walls are absent in fine grained $\mathrm{MnZn}$-ferrites [5]. Thus for $\mathrm{D}<3.8 \mu \mathrm{m}$ the Globus model cannot apply and the initial permeability must be rotational in origin. Furthermore, the entire grain size dependence of the permeability (up to $\mathrm{D}=16 \mu \mathrm{m}$ ) could be described by the NMGB-model, without discontinuity at the transition from the mono- to two domain state. This shows that also for two- domain MnZnferrites, which do contain an intra-granular domain wall, the permeability is rotational in origin. However, the MnZn-ferrites studied in ref. [5] have a low anisotropy, the anisotropy constant $K$ was only $32 \mathrm{~J} / \mathrm{m}^{3}$. In ferrites with higher $\mathrm{K}$ the initial permeability might not be rotational. Therefore, the grain size dependence of the initial permeability of a $\mathrm{MgMnZn}$-ferrite was investigated. Additionally, the nature of the "non"-magnetic grain boundary was investigated by a study of initial permeability versus grain size at various temperatures. Until now, a study of the nature of the "non"-magnetic grain boundary had led to the suggestion that the nature of the grain boundary in polycrystalline ferrites is hard magnetic rather than nonmagnetic [5]. As the anistropy of a hard-magnetic grain boundary might depend on temperature, the "non"-magnetic grain boundary thickness ( $\delta$ ) was determined as a function of temperature.

\section{EXPERIMENTAL}

Ferrites with composition $\mathrm{Mg}_{0.8} \mathrm{Zn}_{02} \mathrm{Mn}_{0.1} \mathrm{Fe}_{1.85} \mathrm{O}_{3.925}$ were prepared by conventional ceramic processing. This composition was chosen such that the Curie temperature is higher than $200^{\circ} \mathrm{C}$ and that the saturation magnetisation is maximum at about $100^{\circ} \mathrm{C}$. The resistivity is maximized by making an Fe deficient ferrite. Manganese is added to also reduce eddy current losses. By using different milling procedures and by adjusting the sinter temperature between $1100^{\circ} \mathrm{C}$ and $1350^{\circ} \mathrm{C}$ ferrites with a grain size between 0.5 and $8.0 \mu \mathrm{m}$ were obtained. The mean linear intercept, $\mathrm{D}$, was taken as a measure of grain size, because it gives an unequivocal definition of $\mathrm{D}$, independent of the grain shape. Porosities were between 2 and $10 \%$. The initial permeability was measured from -50 to $250{ }^{\circ} \mathrm{C}$ at a frequency of $10 \mathrm{kHz}$ and an induction level $\mathrm{B} \approx 0.04 \mathrm{mT}$. The magnetic domain size was measured by neutron depolarisation [5].

\section{RESULTS AND DISCUSSION}

The initial permeability vs. grain size for $\mathrm{Mg}_{0.8} \mathrm{Zn}_{0.2} \mathrm{Mn}_{0.8} \mathrm{Fe}_{1.85} \mathrm{O}_{3.925}$ is given in fig.1. To account for variations in porosity, which is larger in the finer grained materials, the permeability data were corrected using the expression $[2]: \mu_{i}(e f f)^{c o r r}=\mu_{i}(e f f) .(1+p / 2) /(1-p)$ in which $p$ is the porosity. The curve is a least squares fit based on the NMGB model $[2,3]$ : 


$$
\mu_{i}(e f f)=\frac{\mu_{i} \cdot D}{\mu_{i} \cdot \delta+D}
$$

in which $\mu_{i}$ is the intrinsic initial permeability and $\delta$ the "non"-magnetic grain boundary thickness. With $\mu_{i}=329 \pm 31$ and $\delta=9.4 \pm$ $0.7 \mathrm{~nm}$ a reasonable fit is obtained. In an independent neutron depolarisation experiment the domain size was determined versus grain size. The transition from mono- to two domain state occurs at a critical grain size $D_{c}=2.9 \pm 0.2 \mu \mathrm{m}$. Thus, the permeability data show no contribution from the intra-granular domain wall at $\mathrm{D}_{\mathrm{c}}>2.9 \mu \mathrm{m}$, contrary to predictions of the Globus model [1]. This indicates that the low induction permeability is rotational in origin both above and below $\mathrm{D}_{\mathrm{c}}$. The same was found for $\mathrm{MnZn}$-ferrite and is probably due to the low anisotropy $\mathrm{K}$ of $\mathrm{MnZn}$-ferrite[5]. Apparently, also at the higher $\mathrm{K}$ of this $\mathrm{MgMnZn}$-ferrite (of about $72 \mathrm{~J} / \mathrm{m}^{3}$ ) the permeability is still predominantly rotational, also when intra-granular domain walls are present.

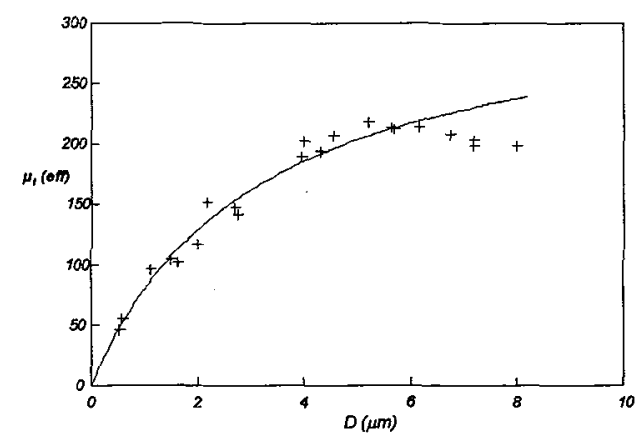

Figure 1: Initial permeability, $\mu_{i}($ eff $)$, versus grain size $D$ for the $\mathrm{MgMnZn}$-ferrite. Measurements were performed at $20^{\circ} \mathrm{C}$.

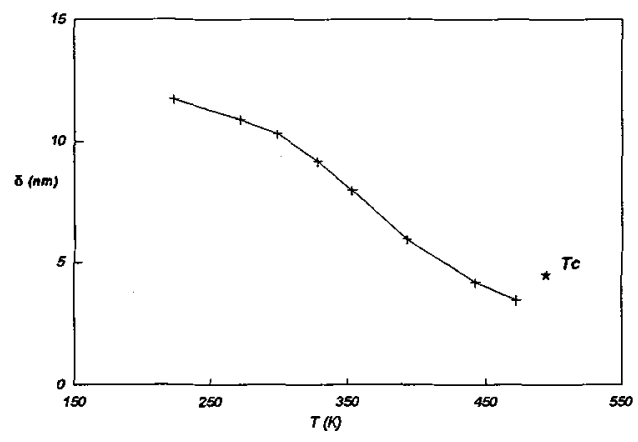

Figure 2: Temperature dependence of $\delta$ values obtained from fits of $\mu_{i}(\mathrm{eff})$ vs. $D$ and calculated from $\mu_{j}$ (eff) at $T_{c}$.

For $\mathrm{D}>5 \mu \mathrm{m}$ an increasing deviation between measurement data and the solid curve exists in figure 1 . This suggests that 8 increases with grain size. To obtain information on individual $\delta$ 's, $\mu_{i}\left(\right.$ eff) was determined at the Curie temperature $T_{c}$ for each grain size (at $T_{c}$ : $\mu_{\mathrm{i}} \rightarrow \infty$ thus, $\delta=\mathrm{D} / \mu(\mathrm{eff})$ ). It followed that $\delta=4.5 \pm 0.9 \mathrm{~nm}$ for $\mathrm{D}<5 \mu \mathrm{m}$ and $\delta=6.1 \pm 1.2 \mathrm{~nm}$ for $\mathrm{D}>5 \mu \mathrm{m}$. Further analysis showed, however, that large grained samples (obtained at somewhat higher sinter temperatures) contain intragranular pores. The increase in $\delta$ is therefore, only an apparent effect, originating from a decrease of the "intrinsic" permeability of the ferrite by these intragranular pores.

Van der Zaag et al. [5] have suggested that $\delta$ is a hard-magnetic grain boundary, rather than a "non"-magnetic grain boundary. A hard-magnetic grain boundary may loose some of its anisotropy with increasing temperature. Consequently, $\delta$ may appear to be smaller at higher temperatures. The observed difference between $\delta$ obtained at $T_{c}$ and at $20^{\circ} \mathrm{C}$ suggests such a temperature effect. Additional data was obtained from fits of the permeability versus grain size at different temperatures. The results are shown in fig.2. (Grains with $\mathrm{D}>5.2 \mu \mathrm{m}$ were not taken into account, because of the decrease in intrinsic permeability). Indeed $\delta$ seems to depend on $T$, supporting the idea of a hard magnetic grain boundary. Since at $T_{c}, \mu_{i}($ eff) used in calculating $\delta$ was obtained from permeability vs. temperature measurements at intervals of $2^{\circ} \mathrm{C}, \mu_{i}(\mathrm{eff})$ is most likely somewhat lower than the actual $\mu_{i}(\mathrm{eff})$ at $\mathrm{T}_{c}$. Therefore, $\delta$ 's at $T_{c}$ are systematically too high and, hence, the average value of $4.5 \pm 0.9 \mathrm{~nm}$ does not fit exactly in the curve drawn in fig. 2 .

\section{CONCLUSIONS}

The effective initial permeability for the $\mathrm{MgMnZn}$-ferrite studied, increases gradually with grain size from $\mathrm{D}=0.5$ to $\mathrm{D}=8.0 \mu \mathrm{m}$. This cannot be explained by the Globus model, since for $\mathrm{D}<2.9 \mu \mathrm{m}$ intra- granular domain walls are absent. Permeability data are in good accordance with the nonmagnetic grain boundary model, both for $\mathrm{D}<2.9 \mu \mathrm{m}$ and for $\mathrm{D}>2.9 \mu \mathrm{m}$. This suggests that the initial permeability is predominantly rotational. Disagreement between the NMGB model and experimental data for D $>5 \mu \mathrm{m}$ is explained by intragranular porosity. We find that the "non"-magnetic grain boundary thickness as defined in the NMGB model depends on temperature. It should therefore, at least in part, be regarded as a hard magnetic grain boundary [5].

\section{References}

[1] Globus A., J. Phys. (Paris) Colloq., C1 (1977) 1-15.

[2] Rikukawa H. IEEE Trans. Magn., MAG-18 (1982) 1535-1537.

[3] Visser E.G. and Johnson M.T. , J. Magn. Magn. Mater., 101 (1991) 143-147.

[4] Snoek J.L., Physica, 14 (1948) 207-217.

[5] van der Zaag P.J., Ruigrok J.J.M., Noordermeer A., van Delden M.H.W.M., Por P.T., Rekveldt M.Th., Donnet D.M. and Chapman J.N. , J. Appl. Phys., 74 (1993) 4085-4095. 